\title{
Türkiye'de Çevresel Kuznets Eğrisi Hipotezinin Test Edilmesi: Yapısal Kırılmalı Eşbütünleşme Testi ile Hata Düzeltme Modelinden Kanıtlar ${ }^{1}$
}

\author{
Validity of Environmental Kuznets Curve Hypothesis for Turkey: Evidences \\ from Co-Integration Test With a Structural Break and Error Correction \\ Mechanism
}

\section{Reşat CEYLAN ${ }^{2}$ a \\ Güray Enes KARAAĞAÇ3}

\footnotetext{
2 Pamukkale Üniversitesi, İ.İ.B.F. İktisat Bölümü rceylan@pau.edu.tr Orcid ID: 0000-0003-3727-6644

${ }^{3}$ Bilkent Üniversitesi Ekonomi Bölümü Yüksek Lisans Öğrencisi gekaraagac@gmail.comOrcid ID: 0000-0001-6229-8533

aYazı̧ılan yazar/Corresponding author
}

$\begin{array}{ll}\text { Makale Bilgisi: } & \text { Araştırma Makalesi } \\ \text { Geliş Tarihi: } & 24.08 .2020 \\ \text { DüzeltmeTarihi: } & 04.09 .2020 \\ \text { Kabul Tarihi: } & 07.09 .2020\end{array}$

Özet

Bu çalışmanın temel amacı Türkiye için 1960-2014 döneminde Çevresel Kuznets Ĕ̆risi (EKC) hipotezini, kişi başı karbondioksit miktarı, kişi başı gelir düzeyi ve kişi başı enerji tüketimi değişkenlerini kullanarak analiz etmektir. $\mathrm{Bu}$ amaçla, Gregory-Hansen yapısal kırılmalı eşbütünleşme tekniŏi kullanılmıştır. Elde edilen bulgular, Türkiye'de EKC hipotezinin geçerli olmadığını, değişkenler arasında yapısal kırılmalı eş-bütünleşme ilişkisinin bulunduğunu ve hata düzeltme mekanizmasının çalıştı̆̆ııı göstermektedir. Tahmin edilen Çevresel Kuznets Ĕ̆risinin biçimi N şeklindedir. Ekonomik büyümenin yaşandığı ilk periyotta çevresel kirlilik artmakta ve belirli bir refah seviyesine ulaşınca azalmakta olsa da ilerleyen süreçte çevresel kirlilik artmaktadır. ECM tahminlerine göre ise kişi başı gelir düzeyi ve kişi başı enerji tüketiminden kaynaklanan şokların \%81'i bir dönem içinde giderilmekte ve sistem yeniden uzun dönem dengesine gelmektedir.

Anahtar Kelimeler: Çevresel Kuznet Ĕ̆risi, Yapısal kırılmalı eş bütünleşme testi, Çevre kirliliği, Türkiye

JEL kodlarn: O13, Q56, Q57

$\begin{array}{ll}\text { Article Info: } & \text { Research Article } \\ \text { Date Submitted: } & 24.08 .2020 \\ \text { Date Revised: } & 04.09 .2020 \\ \text { Date Accepted: } & 07.09 .2020\end{array}$

Abstract

The main purpose of this study is to determine the validity of Environmental Kuznets Curve(EKC) hypothesis for Turkey by CO2 per capita, GDP per capita, and Energy consumption per capita variables in 1960-2014 sample period. For this purpose, the GregoryHansen co-integration method with a structural break was used. Empirical evidences reveal that the EKC hypothesis is not valid, co-integration relationship with structural break exists among the variables, and the error correction mechanism works. Estimated Environmental Kuz-nets Curve is N shaped. The first period in which economic growth occurs, environmental pollution increases and after reaching a certain welfare level decreases. However, environmental pollution increases during the following period. According to ECM estimations, $81 \%$ of the shocks that arise from GDP per capita and energy consumption per capita are eliminated in one period and the system reaches to long-run equilibrium again.

Keywords: Environmental Kuznets Curve, Cointegration Test with Structural Break, Environ-mental Pollution, Turkey.

JEL codes: O13, Q56, Q57

\footnotetext{
${ }^{1}$ Çalışma etik kurul ve yasal izin alınması kapsamında değildir. İntihal raporu alınmıştır.
} 


\section{GÍRIŞ}

Çevresel Kuznets Eğrisi (EKC) Hipotezi, kişi başı gelir ile çeşitli çevre kirliliği değişkenleri arasındaki ilişkiye odaklanır. Bu hipoteze göre; ekonomik büyümenin başlangıç aşamalarında kirlilik artar ve çevresel kalite azalır, ancak kişi başına düşen gelirde bir eşik düzeye ulaşıldıktan sonra diğer ekonomik değişkenlerin de etkisi ile kişi başı gelir düzeyi artarken çevresel kirlilik azalır. EKC hipotezi, kişi başı çevresel kirlilik göstergeleri ile kişi başı gelir düzeyi arasında ters-U biçimli bir fonksiyonel ilişki olduğunu ima eder (Dinda, 2004). Bu hipotez, son otuz yıldır birçok iktisatçının ilgisini çekmektedir. EKC hipotezinin ilk ampirik uygulaması Grossman ve Krueger (1991) tarafından yapılmış ve bu çalışma ile birlikte zengin bir literatür oluşmuştur.

Geleneksel çevreci görüş, 1980'lerde popüler olan sürdürülebilir kalkınma görüşünün aksine, üretim sürecinde çevre dostu teknolojilerin kullanımından bağımsız olarak ekonomik faaliyetlerin çevresel etkilerinin oluşabileceğini öne sürmektedir (Stern, 2017). IPAT (Impact (etki)=pollution(kirlilik)*affluence(refah)*technology(teknoloji)) özdeşliği tarafından tanımlanan geleneksel çevreci görüşe göre, eğer servet, kişi başı gelir ise teknoloji terimi etki ya da emisyonlardır. Diğer yandan, Geleneksel çevreci görüşün tersine, sürdürülebilir kalkınma kavramına göre, çevresel kirlilik oluşmadan da sürdürülebilir kalkınma sağlanabilir. Ayrıca yoksulluğun azaltılması için çevresel korunma zorunludur. Dünyada ekonomik büyüme-çevre tartışmalarının 1980 öncesinde de dile getirildiği bilinmektedir.

1972 yılında Roma Kulübü tarafından hazırlatılan "Büyümenin Sınırları” raporuna göre; ekonomik büyüme sürecinin çevresel etkileri vardır. Ayrıca, yakın gelecekte dünya yenilenemez enerji kaynaklarının kullanımında fiziksel limite ulaşacağı için ekonomik büyüme süreci de duracaktır. Yine aynı raporda, yenilenemez enerji kaynaklarının yoğun kullanımının, tarımsal üretimde bozulma ve aşırı çevresel kirlenmeye de yol açacağ belirtilmiştir. Diğer yandan, Dünya Bankası'nın 1992 yılında yayınlanan ve EKC hipotezini popüler hale getiren "Dünya Kalkınma Raporu"na göre; artan ekonomik aktivitelerin çevreye geri döndürülemez bir şekilde zarar verdiği görüşü, teknolojik tercihler ve çevresel yatırımlar üzerine yapılan statik varsayımlara dayanır. Ayrıca, gelir arttıkça yatırımlar için ulaşılabilir kaynaklar artar, bu nedenle çevresel kalitenin iyileştirilmesi yönünde talep de artar (Kaika ve Zervas, 2013).

Stern (2017)'ye göre EKC hipotezi aşağıdaki 'yaklaşık faktörler' ile açıklanabilir:

Üretim ölçeği artarken sektörel çeşitlilik ile birlikte çevre faktörü ön plana çıkar.

Farklı sektörler, farklı kirlilik yoğunluğuna sahiptir. Tipik olarak, ekonomik gelişme süreci boyunca üretim içeriği değişir. Bu durum, çeşitlilik etkisi olarak isimlendirilir.

Girdi içeriği, çevreye daha az zararlı girdilerden, çevreye daha çok zarar veren girdi içeriklerine dönüşmektedir ve tersi.

Teknolojideki gelişmeler aşağıdaki iki faktörü de içermektedir

Diğer faktörler sabit iken çıktı başına kirlilik yaratan girdilerin daha az kullanımı yoluyla üretim etkinliği sağlanır. 
Emisyon spesifik değişim süreci, potansiyel kirlilik yaratan girdi başına daha az kirlilik salınımıyla sonuçlanır.

Üçüncü ve dördüncü faktörler birlikte sıklıkla teknik etki olarak bilinir (Copeland ve Taylor, 2004). Bu yaklaşık faktörler, daha farklı temellere dayanan çevresel düzenleme veya inovasyon politikaları gibi değişkenlerdeki dönüşümlerden etkilenir. Dolayısıyla, bu noktada ekonomik büyüme çevresel problemlerin nedeni mi? Yoksa, ekonomik büyüme çevresel problemleri çözme sürecinin önemli bir parçası mı? Soruları akla gelmektedir (Dinda, 2004). Bu sorular, 1990'lı yıllardan itibaren ekonomistlerin ilgi odağ EKC hipotezini test eden birçok çalışma yapılmıştır.

Bu çalışmanın temel amacı, Türkiye'de EKC hipotezini 1960-2014 dönemi için test etmektir. Çalışmanın geri kalanı aşağıdaki gibi organize edilmektedir: Takip eden bölümde ilgili literatür sunulmakta, üçüncü bölümde EKC hipotezinin teorik arka planı verilmekte ve metodoloji açıklanmakta, dördüncü bölümde veri seti tanıtılmakta, son bölümde ise çalışmanın bulguları ve politika çıkarımlarına yer verilmektedir.

\section{LITERATÜR}

Simon Kuznets'in 1955 yılındaki çalışmasından uyarlanan Çevresel Kuznets Eğrisi'nin ilk uygulamalı çalışmaları 1990'11 yılların başlarına dayanır. Bu çalışmalara Selden ve Song (1994), Grossman ve Krueger (1991, 1995) örnek olarak gösterilebilir. Sonraki y1llarda bu hipotezi test eden çalışmaların sayısı hızla artmıştır. Sürdürülebilir kalkınma kavramının literatürde yer edinmesi, 1997 yılında imzalanan Kyoto protokolü ve çevresel faktörlerin daha popüler hale gelmesi bu alanda yapılan çalışmaların artmasına neden olmuştur.

EKC hipotezini ele alan çalışmalara bakıldığında, kullanılan ekonometrik teknikler, ele alınan ülkeler ve incelenen zaman dilimine bağlı olarak faklı sonuçlara ulaşıldığı anlaşılmaktadır. Bu çalışmalardan bazıları aşağıdaki gibi özetlenebilir:

Luzatti ve Orsini (2009), 113 ülke için 1971-2004 dönemini ele aldıkları çalışmalarında panel veri tekniğini kullanarak EKC hipotezinin geçerliliğini araştırmışlar ve hipotezin geçersiz olduğu yönünde bulgulara ulaşmışlardır. Jalil ve Mahmud (2009) ise, Çin için 1975-2005 dönemini dikkate aldıkları çalışmalarında ARDL ve Granger nedensellik analizlerini kullanarak EKC hipotezinin geçerli olduğunu ortaya koymuşlardır. Akbostancı ve diğ. (2009), Türkiye'de EKC hipotezini sinamak için 1968-2003 ve 1992-2001 dönemlerini ele aldıkları çalışmalarında Johansen eş-bütünleşme ve panel veri analizlerini kullanmışlar ve EKC hipotezinin geçersizliği yönünde bir sonuca ulaşmışlardır. Diğer yandan Iwata ve diğ. (2009), Fransa için EKC hipotezini araştırdıkları çalışmalarında 1960-2003 dönemini incelemişler, ARDL ve Granger nedensellik analizlerini kullanarak hipotezin geçerli olduğunu ileri sürmüşlerdir. Fodha ve Zaghdoud (2010), Tunus için EKC hipotezini test etmişler ve 1961-2004 döneminde Johansen eşbütünleşme ve VECM modellerini kullanarak hipotezin geçerli olduğunu ortaya koymuşlardır. Nasir ve Rehman (2011), Pakistan için 19722008 dönemine ait verileri kullanarak Johansen eş-bütünleşme tekniğini uyguladıkları çalışmalarında EKC hipotezinin lehinde kanıtlar sunmuşlardır. Saboori ve diğ. (2012), Malezya' da EKC hipotezinin geçerliliğini araştırdıkları çalışmalarında 1980-2009 dönemini ele almışlar ve ARDL, Granger nedensellik ve ECM tekniklerini kullanarak hipotezin geçerli olduğu sonucuna ulaşmışlardır. Fosten ve diğ. (2012), 1830-2003 ve 1850-2002 dönemleri için 
Birleşik Krallık'ta EKC hipotezinin geçerliliğini sınadıkları çalışmalarında Eş-bütünleşme, TAR ve M-TAR tekniklerini uygulayarak, anlamlı bulgular elde etmişlerdir. Esteve ve Tamarit (2012), 1857-2007 dönemi için İspanya'da EKC hipotezini test etmişler ve eşik eşbütünleşme ve VECM tekniklerini kullanarak hipotezi destekleyen sonuçlara ulaşmışlardır. Tiwari ve diğ. (2013), Hindistan için 1966-2009 periyotunda ARDL ve Johansen eşbütünleşme tekniklerini kullandıklarını çalışmalarında, EKC hipotezi için anlamlı sonuçlar bulmuşlardır. Lau ve diğ. (2014), 1970-2008 döneminde Malezya'da EKC hipotezini ARDL ve Granger nedensellik teknikleri ile ele almışlar ve geçerlilik lehinde sonuçlara ulaşmışlardır. Farhani ve diğ. (2014), 1990-2010 döneminde 10 orta doğu ve kuzey Afrika ülkesini inceledikleri çalışmalarında panel eş-bütünleşme tekniğini uygulayarak EKC hipotezi lehinde kanıtlar sunmuşlardır. Öztürk ve Al-Mulalı (2015), Kamboçya ekonomisinde 19662012 döneminde EKC hipotezini GMM ve TLS teknikleri ile incelemişler ve geçersizlik lehinde bulgulara ulaşmışlardır. Al-Mulalı ve diğ. (2015), gelire göre sıralanmış 93 ülke'de EKC hipotezini araştırdıkları çalışmalarında 1980-2008 periyotunu ele almışlar ve GMM ve panel veri analizini kullanarak ileri orta ve yüksek gelir gurubunda bulunan ülkelerde EKC hipotezinin geçerli, düşük orta ve düşük gelirli ülkelerde ise geçersiz olduğu bulgusunu elde etmişlerdir. Apergis ve Öztürk (2015), 14 Asya ülkesini inceledikleri çalışmalarında 19902011 periyotunda EKC hipotezinin geçerliliğini GMM ve panel eş-bütünleşme teknikleri ile araştırmışlar ve hipotezin geçerli olduğunu not etmişlerdir. Baek (2015), Arktik ülkelerini 1960-2010 periyotu için ARDL ve eş-bütünleşme yöntemlerini kullnarak incelemiş ve EKC hipotezi lehinde zayıf kanıt elde etmiştir. Bölük ve Mert (2015), Türkiye için EKC hipotezinin geçerliliğini 1961-2010 dönemi için ARDL ve ECM teknikleri ile araştırmışlar ve hipotezin geçerli olduğunu ileri sürmüşlerdir. Son olarak Alam ve diğ. (2016), 1970-2012 dönemi için EKC hipotezini, Brezilya, Çin, Endonezya ve Hindistan ekonomileri için ele almışlar, ARDL ve VECM tekniklerini uygulayarak Hindistan haricindeki ülkelerde hipotezin geçerli olduğu sonucuna varmışlardır.

Sonuç olarak EKC hipotezinin son 30 yılda ekonomistlerin ilgi odağında olduğu ve bu konuda oldukça zengin bir literatürün oluştuğunu söylemek mümkündür. Ekonomik büyüme sürecinin sürdürülebilirliği tartışmalarında çevre kirliliğinin merkezi bir role sahip olduğu açıtır. Ayrıca dünya ekonomisinde kayda değer ölçüde, çevre kirliliğinin enerji kaynaklarının etkin kullanımını gerektirdiği ve bu konuda uluslararası platformların giderek daha önemli hale geldiği de tartışma götürmez bir gerçektir.

\section{TEORÍK ARKA PLAN VE METODOLOJİ}

Kuznets (1955) çalışmasını temel alan EKC hipotezi, ekonomik büyüme sırasında ortaya çıkan çevresel kirliliğin ekonomik büyüme sürecinde kendiliğinden elimine olacağını öne sürmektedir.

EKC hipotezine göre gelişmekte olan bir ülkede kişi başı gelir artışı yaşanırken çevresel kirlilik ilk etapta artar. Bu duruma neden olarak devletlerin ekonomik büyümeyi sürdürebilmek için çevresel faktörleri göz ardı etmesi ya da insanların işlerini çevresel faktörlere tercih etmesi gösterilebilir. Daha sonraki aşamada belirli bir kişi başı gelir seviyesine ulaşıldıktan sonra toplumsal bilincin oluşması ve/veya korumacı politikalar ile kişi başı çevresel kirlilik azalır. 
Literatürde Çevresel Kuznets Eğrisi hipotezi analiz edilirken yaygın olarak kullanılan iki model mevcuttur.

$$
\begin{aligned}
& Y=\alpha+\beta_{1} X_{1}+\beta_{2} X_{2}^{2}+\varepsilon \\
& \text { ve } \\
& Y=\alpha+\beta_{1} X_{1}+\beta_{2} X_{2}^{2}+\beta_{3} X_{3}^{3}+\beta_{4} Z+\varepsilon
\end{aligned}
$$

Her iki modelde de $Y$, kişi başı çevresel kirlenmeyi; $X$, kişi başı geliri; $Z$, kontrol değişkenleri vektörünü temsil etmektedir. Kurulan modeldeki değişkenlerin katsayılarının işaretlerine göre ilişki biçimlenmektedir. EKC'nin şekillenebileceği yedi durum Dinda (2004), Kijima ve diğ. (2010) ve Kaika ve Zervas (2013) çalışmalarında aşağıdaki gibi listelenmiştir.

i. $\quad \beta_{1}=\beta_{2}=\beta_{3}=0$. Düz bir ilişki ya da $\mathrm{X}$ ve $\mathrm{Y}$ arasında ilişki yok.

ii. $\quad \beta_{1}>0$ ve $\beta_{2}=\beta_{3}=0$. X ve $\mathrm{Y}$ arasında monoton artan veya lineer bir ilişki.

iii. $\quad \beta_{1}<0$ ve $\beta_{2}=\beta_{3}=0$. X ve $\mathrm{Y}$ arasında monoton azalan bir ilişki.

iv. $\quad \beta_{1}>0, \beta_{2}<0$ ve $\beta_{3}=0$. $X$ ve $Y$ arasında ters $U$ biçimli ilişki yani Çevresel Kuznets Eğrisi.

v. $\beta_{1}<0, \beta_{2}>0$ ve $\beta_{3}=0$. X ve $\mathrm{Y}$ arasında $\mathrm{U}$ biçimli ilişki.

vi. $\quad \beta_{1}>0, \beta_{2}<0$ ve $\beta_{3}>0$. X ve $\mathrm{Y}$ arasında kübik polinom ya da $\mathrm{N}$ biçimli ilişki.

vii. $\quad \beta_{1}<0, \beta_{2}>0, \beta_{3}<0$. $\mathrm{X}$ ve $\mathrm{Y}$ arasında ters $\mathrm{N}$ biçimli ilişki.

\subsection{Zivot-Andrews Yapısal Kırılmalı Birim Kök Testi}

Makroekonomik zaman serilerinin çeşitli nedenlerle maruz kaldıkları şokların etkisi ile yapısal kırılmaya uğrayabileceği gerçeğinden hareketle Zivot ve Andrews (1992), ele alınan serilerde tek yapısal kırılmaya izin veren birim kök süreci için aşağıdaki üç modeli tanımlamaktadır.

Model A: $\mathrm{Y}_{\mathrm{t}}=\mathrm{a}+\mathrm{bt}+\mathrm{dY}_{\mathrm{t}-1}+\mathrm{c}_{1} \mathrm{DU}(\lambda)+\sum_{\mathrm{i}=1}^{\mathrm{k}} \mathrm{d}_{\mathrm{i}} \Delta \mathrm{Y}_{\mathrm{t}-\mathrm{i}}+\varepsilon_{\mathrm{t}}$

Model B: $\mathrm{Y}_{\mathrm{t}}=\mathrm{a}+\mathrm{bt}+\mathrm{d} \mathrm{Y}_{\mathrm{t}-1}+\mathrm{c}_{2} \mathrm{DT}(\lambda)+\sum_{\mathrm{i}=1}^{\mathrm{k}} \mathrm{d}_{\mathrm{i}} \Delta \mathrm{Y}_{\mathrm{t}-\mathrm{i}}+\varepsilon_{\mathrm{t}}$

Model C: $\mathrm{Y}_{\mathrm{t}}=\mathrm{a}+\mathrm{bt}+\mathrm{dY_{ \textrm {t } - 1 }}+\mathrm{c}_{1} \mathrm{DU}(\lambda)+\mathrm{c}_{2} \mathrm{DT}(\lambda)+\sum_{\mathrm{i}=1}^{\mathrm{k}} \mathrm{d}_{\mathrm{i}} \Delta \mathrm{Y}_{\mathrm{t}-\mathrm{i}}+\varepsilon_{\mathrm{t}}$

Her üç model için de boş hipotez yapısal kırılma durumunda birim kökün varlığını ortaya koymaktadır. Ayrıca, DU ve DT terimleri sırası ile düzeydeki ve eğimdeki yapısal kırılmayı temsil eden kukla değişkenler olarak modelde yer almaktadır.

$$
D U(\lambda)=\left\{\begin{array}{ll}
1, & t>T_{B} \\
0, & t \leq T_{B}
\end{array} \text { ve } D T(\lambda)=\left\{\begin{array}{rc}
t-T \lambda, & t>T \lambda \\
0, & t \leq T_{B}
\end{array}\right.\right.
$$

$\mathrm{t}=1,2,3, \ldots, \mathrm{T}$ olmak üzere zamanı göstermekte iken T_B yapısal kırılma tarihini, $\lambda=T \_B / T$, ise kırılma zamanını göstermektedir.

\subsection{Hansen İstikrarsızlık Testi Ve Gregory-Hansen Yapısal Kırılmalı Eşbütünleşme Testleri}

Hansen (1992) tarafından geliştirilen istikrarsızlık testi, ele alınan değişkenler arasındaki eşbütünleşme ilişkisinin sahte olma olasılığını ortadan kaldırmayı amaçlamaktadır. Bu nedenle Hansen (1992) istikrarsızlık testi, çok değişkenli bir standart eşbütünleşme denkleminden hareket edilerek türetilmiştir.

$y_{t}=A_{t} x_{t}+u_{t}, t=1,2, \ldots, n$.

(6) Denkleminde yer alan $y_{t}$ ve $x_{t}$ zaman içinde değişim gösteren ve ilişkili olabileceği düşünülen iki seridir. Burada, boş hipotez $A_{t}$ katsayısının zaman içerisinde sabit olduğudur. $\mathrm{Bu}$ amaçla analizde, Lc, SubF ve MeanF testleri kullanılarak ele alınan değişkenler arasındaki 
uzun dönem ilişkinin istikrarsız olup olmadığı incelenir. Boş hipotezin kabul edilmesi durumunda değişkenler arasındaki ilişkinin istikrarlı olduğuna karar verilir. Diğer yandan yapısal kırılmalı eşbütünleşme analizlerinde değişkenler arasındaki uzun dönemli ilişkinin istikrarsız olması gerekli olmaktadır. Analizin alternatif hipotezi, bilinmeyen bir zamanda yapısal kırılmanın varlığı altında, uzun dönem eşbütünleşme ilişkisinin istikrarlı olmadiğıdır.

Kırılma zamanının bilinmediği Chow testine dayanan MeanF ve SubF testleri uygulanırken veri $[0.15,0.85]$ oranında kırpılmaktadır. Üç testin de boş hipotezleri aynı olsa da hangi testin kullanılacağı, testin amacına göre seçilmelidir. Eğer amaç eşbütünleşme vektöründe ani bir kırılmayı, hem sabit terimde hem de eğim katsayısında araştırmaksa SubF testinin kullanılması uygundur. Eğer, testin amacı kurulan modelin istikrarlı bir ilişkiyi yakalayıp yakalayamadığını incelemekse MeanF testi kullanılmalıdır. Lc testi ise örneklem boyunca parametre olabilirliğinin sabit olup olmadığını göstermektedir (Hansen, 1992).

Uzun dönem eşbütünleşme ilişkisinin istikrarlı olmadığı, yani yapısal kırılmanın bulunduğu durumda eşbütünleşme ilişkisinin ortaya konması için Gregory-Hansen(1996a, 1996b) yapısal kırılmalı eşbütünleşme testleri uygulanır. Gregory-Hansen (1996a, 1996b), aşağıdaki modellerden hareketle değişkenler arasındaki olası eşbütünleşme ilişkilerinin ortaya konabileceğini ileri sürmüştür.

Model 1: Standart eşbütünleşmeyi ortaya koyan modeldir.

$y_{t}=\mu+\alpha^{T} X_{t}+e_{t}, t=1,2, \ldots, n$.

$\mathrm{Bu}$ modelde $y_{t}, \mu, \alpha, X_{t}$, sırasıyla bağımlı değişkeni, sabit terimi, eğim katsayısını ve bağımsız değişkeni göstermektedir. $y_{t}$ ve $X_{t}$ fark durağan ve $e_{t}$, düzey durağandır. Sabit terimde ve/veya eğim katsayısında meydana gelen yapısal kırılmayı temsil etmesi için $\varphi$ kukla değişkeni modele dahil edilmiştir.

$$
\varphi_{1 \tau}= \begin{cases}0, & t \leq[n \tau] \\ 1, & t>[n \tau],\end{cases}
$$

$\tau \in(0,1)$ değişim noktasının göreceli zamanını gösterirken $[n \tau]$ tam sayı kısmını temsil etmektedir.

Model 2 (C): Sadece sabit terimdeki kırılmayı dikkate alan modeldir.

$y_{1 t}=\mu_{1}+\mu_{2} \varphi_{1 \tau}+\alpha^{T} X_{t}+e_{t}, t=1,2, \ldots, n$.

Model $3(\mathrm{C} / \mathrm{T})$ : Sabit terimdeki kırılmayı dikkate alan trendli modeldir.

$y_{t}=\mu_{1}+\mu_{2} \varphi_{1 \tau}+\beta t+\alpha^{T} X_{t}+e_{t}, t=1,2, \ldots, n$.

Model 4 (C/S): Sabit terimdeki ve eğim katsayısındaki kırılmayı dikkate alan, trendsiz modeldir. Kısaca trendsiz rejim değişimi modelidir.

$y_{t}=\mu_{1}+\mu_{2} \varphi_{1 \tau}+\alpha_{1}^{T} X_{t}+\alpha_{2}^{T} X_{t} \varphi_{1 \tau}+e_{t}, t=1,2, \ldots, n$.

Model 5: Sabit terimdeki ve eğim katsayısındaki kırılmayı dikkate alan, trendli modeldir. Kısaca trendli rejim değişimi modelidir.

$y_{t}=\mu_{1}+\mu_{2} \varphi_{1 \tau}+\beta_{1} t+\beta_{2} t \varphi_{1 \tau}+\alpha_{1}^{T} X_{t}+\alpha_{2}^{T} X_{t} \varphi_{1 \tau}+e_{t}, t=1,2, \ldots, n$. 
Bu modellerde $\mu_{1}, \alpha_{1}$ ve $\beta_{1}$ sirasiyla yapısal kırılmadan önceki sabit terim, eğim katsayısı ve trend katsayısıdır. $\mu_{2}, \alpha_{2}$ ve $\beta_{2}$ ise sırasıyla yapısal kırılmadan sonraki sabit terim, eğim katsayısı ve trend katsayısıdır.

\subsection{Hata Düzeltme Modeli (ECM)}

Eşbütünleşmenin olduğu durumlarda en az bir tane tek taraflı nedensellik ilişkisi vardır. Hata düzeltme modeli, kısa ve uzun dönemli nedenselliğin belirlenmesinde kullanılan modellerden biridir.

$\Delta Y_{t}=\alpha_{1}+\alpha_{y} \mu_{t-1}+\sum_{i=1} \alpha_{11}(i) \Delta Y_{t-i}+\sum_{i=1} \alpha_{21}(i) \Delta X_{t-i}+\varepsilon_{y t}$,

$\Delta \mathrm{X}_{\mathrm{t}}=\alpha_{1}+\alpha_{x} \mu_{t-1}+\sum_{i=1} \alpha_{11}(i) \Delta Y_{t-i}+\sum_{i=1} \alpha_{12}(i) \Delta X_{t-i}+\varepsilon_{x t}$

$\mathrm{Bu}$ modelde $Y_{t}$ ve $\mathrm{X}_{\mathrm{t}}$ fark durağan iki zaman serisi iken $\varepsilon_{y t}$ ve $\varepsilon_{x t}$ aralarında korelasyon ilişkisi bulunmayan hata terimlerini temsil etmektedir. $\mu_{t-1}$, bir diğer adıyla Hata Düzeltme Terimi(ECT), eşbütünleşme denkleminden elde edilmiş, düzeyde durağan hata terimi seridir. Buna göre; hata düzeltme teriminin katsayısı $\left(\alpha_{y}, \alpha_{x}\right)$ istatistiksel olarak anlamlı ve $(0,-1)$ aralığında değer alıyor ise hata düzeltme mekanizması çalışmaktadır ve uzun dönem nedensellik ilişkisi bulunmaktadır. Seriye etki eden bir şok, bir dönemde $\left(\alpha_{y}, \alpha_{x}\right)^{*} 100$ oranında etkisini kaybeder ve seri uzun dönem dengesine ulaşır. Eğer, açıklayıcı değişken ile hata düzeltme terimine uygulanan birleşik F testi (WALD testi) sonucu elde edilen F istatistiği anlamlı ise açıklayıcı değişken, açıklanan değişkenin güçlü Granger nedenidir.

\section{VERİ SETI}

Bu çalışmada Türkiye için Çevresel Kuznets Eğrisi hipotezi 1960-2014 örneklem döneminde CO2 (metrik ton), enerji tüketimi (kg eş değeri petrol tüketimi), reel GSYİH (2010 baz yıll, dolar cinsinden sabit fiyatlar) değişkenleri ile test edilmiştir. Tüm değişkenler kişi başı cinsindendir. Aşağıdaki tabloda değişkenlerin tanımlayıcı istatistikleri listelenmiştir.

Tablo 1: Tanımlayıcı İstatistikler

\begin{tabular}{|c|c|c|c|}
\hline Değişken & $\mathrm{CO}_{2}$ & GDP & $\mathrm{E}$ \\
\hline Ortalama & 2.42301 & 6704.866 & 909.515 \\
\hline Medyan & 2.42653 & 6308.635 & 908.411 \\
\hline Maksimum & 4.49148 & 13312.02 & 1585.4 \\
\hline Minimum & 0.61227 & 3134.677 & 385.471 \\
\hline Standart sapma & 1.12801 & 2648.732 & 351.934 \\
\hline Çarpıklık & 0.14561 & 0.729085 & 0.29331 \\
\hline Basıklık & 1.93538 & 2.706452 & 2.04206 \\
\hline Jarque-Bera & 2.79178 & 5.070159 & 2.89155 \\
\hline Olasılık & 0.24761 & 0.079255 & 0.23556 \\
\hline Toplam & 133.265 & 368767.6 & 50023.3 \\
\hline $\begin{array}{c}\text { Karesel sapmaların } \\
\text { toplam1 }\end{array}$ & 68.7094 & $3.79 \mathrm{E}+08$ & 6688311 \\
\hline $\begin{array}{c}\text { Gözlem sayı1 } 1 \\
\text { Kurulan model as̆ğ }\end{array}$ & 55 & 55 & 55 \\
\hline
\end{tabular}

Kurulan model aşağıda yer almaktadır.

$\ln C O_{2}=\alpha+\beta_{1} \ln Y+\beta_{2} \ln Y^{2}+\beta_{3} \ln Y^{3}+\beta_{4} \ln E+\varepsilon$ 
$\ln \mathrm{CO}_{2}$, kişi başı $\mathrm{CO}_{2}$ miktarının doğal logaritmasını temsil etmekte iken $\ln Y$ ve $\ln E$ sırasıyla doğal logaritması alınmış kişi başı reel GSYİH ve doğal logaritması alınmış kişi başı enerji tüketimini temsil etmektedir. Bütün değişkenler World Development Indicators'ten alınmıştır. Ölçeği küçültmek ve tahmin edilen katsayıları esneklik olarak yorumlamak için değişkenlerin doğal logaritmaları alınmıştır.

Yukarıdaki modelde (denklem 14) Çevresel Kuznets Eğrisi hipotezinin geçerli olabilmesi için $\beta_{1}>0, \beta_{2}<0$ ve $\beta_{3}=0$ olmalidır.

\section{BULGULAR}

Nelson ve Plosser (1982), birçok makroekonomik değişkenin birim kök içerdiğini ve birim kök içeren serilerin doğrudan ekonometrik analizlerde kullanılmasının doğru olmadığını belirtmişlerdir. Birim kökün varlığını belirleyebilmek için ADF birim kök testi ve ZivotAndrews yapısal kırılmalı birim kök testi yapılmıştır.

Tablo 2: ADF Testi

\begin{tabular}{|c|c|c|c|c|}
\hline Değişken & Düzey & Fark & Model & Karar \\
\hline $\ln \mathrm{CO}_{2}$ & -2.5933 & $-8.117^{*}$ & $\tau_{\tau}$ & $\mathrm{I}(1)$ \\
\hline $\ln Y$ & 0.2109 & $-7.207^{*}$ & $\tau_{\mu}$ & $\mathrm{I}(1)$ \\
\hline $\ln Y^{2}$ & 0.4755 & $-7.1444^{*}$ & $\tau_{\mu}$ & $\mathrm{I}(1)$ \\
\hline $\ln Y^{3}$ & 0.7336 & $-7.0626^{*}$ & $\tau_{\mu}$ & $\mathrm{I}(1)$ \\
\hline $\ln E$ & -1.2091 & $-7.1557^{*}$ & $\tau_{\mu}$ & $\mathrm{I}(1)$ \\
\hline
\end{tabular}

*, \%1 düzeyinde anlamlılığı temsil etmektedir.

$\tau_{\mu}$ : Sabit terimli modeli temsil etmektedir.

$\tau_{\tau}$ : Sabit terimli ve trendli modeli temsil etmektedir.

ADF testine göre düzey değerinde olan serilerin durağan olmadığını belirten sıfır hipotez reddedilememiştir. Serilerin birinci farkları alınarak oluşturulan seriler ise durağandır.

Tablo 3: Zivot-Andrews Yapısal Kırılmalı Birim Kök Testi

\begin{tabular}{|c|c|c|c|c|}
\hline Değişken & Düzey & Fark & Model & Karar \\
\hline \multirow{2}{*}{$\ln \mathrm{CO}_{2}$} & -3.8816 & $-9.0775^{*}$ & \multirow{2}{*}{$\mathrm{C}$} & \multirow{2}{*}{$\mathrm{I}(1)$} \\
\hline & $1971(0)$ & $1982(0)$ & & \\
\hline \multirow{2}{*}{$\ln Y$} & -3.6702 & $-7.5411^{*}$ & \multirow{2}{*}{$\mathrm{C}$} & \multirow{2}{*}{$\mathrm{I}(1)$} \\
\hline & $1979(0)$ & $2003(0)$ & & \\
\hline \multirow{2}{*}{$\ln Y^{2}$} & -3.7110 & $-7.5227 *$ & \multirow{2}{*}{$\mathrm{C}$} & \multirow{2}{*}{$\mathrm{I}(1)$} \\
\hline & $1999(0)$ & $2003(0)$ & & \\
\hline \multirow{2}{*}{$\ln Y^{3}$} & -3.8347 & $-5.6656^{*}$ & \multirow{2}{*}{$\mathrm{C}$} & \multirow{2}{*}{$\mathrm{I}(1)$} \\
\hline & $2001(0)$ & $2004(3)$ & & \\
\hline \multirow{2}{*}{$\ln E$} & -4.4678 & $-7.7105^{*}$ & \multirow{2}{*}{$\mathrm{C}$} & \multirow{2}{*}{$\mathrm{I}(1)$} \\
\hline & $1979(0)$ & $1978(0)$ & & \\
\hline
\end{tabular}

*, \%1 düzeyinde anlamlılığı temsil etmektedir.

Tablo 3'te Zivot-Andrews yapısal kırılmalı birim kök testi sonuçları yer almaktadır. Tabloda test istatistikleri ve yapısal kırılma yılları belirtilmiştir. Parantez içindeki değerler, gecikme uzunluğunu temsil etmektedir. Model C, sabit terimde ve eğim katsayısında meydana gelen yapısal kırılmanın dikkate alındığı modeldir. Tablo 3 incelendiğinde GSYİH değişkenlerinde meydana gelen yapısal kırılmalar 2003-2004 döneminde iken CO2 ve Enerji tüketimi 
değişkenlerinde meydana gelen yapısal kırılmalar 1978-1982 seneleridir. 1970'li yıllarda ithal ikamesine yönelik sanayi politikaları, 1973 yılında meydana gelen birinci petrol şoku ve OPEC krizi, 1974 Kıbrıs barış harekâtında ülkeye uygulanan ambargo, 1978 yılındaki ikinci petrol şoku bu kırılmalara neden olmuş olabilir. $\ln \llbracket C O \rrbracket \_2, \ln Y, \ln Y^{\wedge} 2, \ln Y^{\wedge} 3$ ve $\ln E$ değişkenlerinin düzey değerleri için sıfır hipotezi, serilerin yapısal kırılma var iken durağan olmadığını belirten hipotez, reddedilememiştir. Serilerin farkları alınarak oluşturulan serilerde ise sıfır hipotezi \%99 güven ile reddedilmiştir. Bulgular, ADF birim kök testi ile tutarlıdır. Seriler I(1)'dir, yani fark durağandır.

$\mathrm{Bu}$ çalışmada, ele alınan serilerin birlikte hareket edip etmediklerini inceleyen bir analiz yöntemi olan eşbütünleşme tekniği kullanılacaktır. Yapısal kırılmanın varlığı altında değişkenler arasındaki eşbütünleşme ilişkisinin incelenmesi için, I(1) olan serilerin doğrudan kullanılabileceği, Johansen eşbütünleşme tekniğine dayanan, Gregory-Hansen yapısal kırılmalı eş bütünleşme tekniğine başvurulacaktır. Bu yöntemin kullanılabilmesi için uzun dönem katsayıların istikrarlılığının test edilmesi gerekmektedir.

Tablo 4: Hansen İstikrarsızlık Testi

\begin{tabular}{|c|c|c|}
\hline Lc & Mean F & Sub F \\
\hline 0.4519 & $7.3804^{* *}$ & $37.1925^{*}$ \\
\hline
\end{tabular}

* ve ** sırasıyla \%1 ve \%5 düzeyinde anlamlılığ temsil etmektedir.

Hansen istikrarsızlık testinin bulgularına göre, MeanF ve SubF testleri ile eşbütünleşme ilişkisinin uzun dönemde istikrarlı olduğunu belirten boş hipotez reddedilmiştir. Bilinmeyen bir zamanda yapısal kırılma olduğunu ve uzun dönem eşbütünleşme ilişkisinin istikrarlı olmadığını belirten alternatif hipotez kabul edilmiştir. Bu nedenle Gregory-Hansen yapısal kırılmalı eşbütünleşme testi uygulanmıştır. Bulgular aşağıdaki tabloda özetlenmiştir.

Tablo 5: Gregory-Hansen Yapısal Kırılmalı Eşbütünleşme Testi

\begin{tabular}{|c|c|c|}
\hline Test & Değer & Model \\
\hline ADF* $^{*}$ & $-6.9178^{* *}$ & \\
${ } }$ & 0 & \\
& \multirow{2}{*}{2} \\
Kirılma T. & 1983 & \\
\hline Zt & $-6.9892^{* *}$ & \\
\hline Kirılma T. & 1984 & \\
\hline
\end{tabular}

**, \%5 düzeyinde anlamlılığ temsil etmektedir.

Analizde sabit terimdeki kırılmayı dikkate alan model 2 kullanılmıştır. ADF* ve Zt testleri ile boş hipotez reddedilmiştir. Yapısal kırılmalı eşbütünleşme ilişkisi söz konusudur. ADF* testine göre yapısal kırılma 1983, Zt testine göre ise 1984 yılında gerçekleşmiştir. 1970'li yıllarda yaşanan siyasi istikrarsızlıklar, 1978-1979 yıllarında yaşanan borç krizi ve ikinci petrol şoku, 24 Ocak 1980 kararları ve 12 Eylül 1980 askeri darbesi yapısal kırılmanın gerçekleşmesine neden olmuş olabilir. Eşbütünleşme denkleminden hesaplanan uzun dönem katsayılar aşağıdaki tabloda listelenmiştir.

Tablo 6: Gregory-Hansen Yapısal Kırılmalı Eşbütünleşme Testi Katsayıları

\begin{tabular}{|c|c|}
\hline Değişken & Katsay 1 \\
\hline$\mu_{1}$ & $-308.1309^{*}$ \\
\hline$\mu_{2} \varphi_{1 \tau}$ & $0.0509^{*}$ \\
\hline
\end{tabular}




\begin{tabular}{|c|c|}
\hline $\ln Y$ & $99.1246^{*}$ \\
\hline $\ln Y^{2}$ & $-10.8182^{*}$ \\
\hline $\ln Y^{3}$ & $0.3938^{*}$ \\
\hline $\ln E$ & $0.8975^{*}$ \\
\hline
\end{tabular}

*, \%1 düzeyinde anlamlılığ temsil etmektedir.

Buna göre; EKC hipotezi için kurulan modelimizde $\beta \_1>0, \llbracket \beta \rrbracket \_2<0$ ve $\beta \_3>0$ 'dır. Bu sonuç, Çevresel Kuznets Eğrisinin N biçimli olduğunu göstermektedir. Kişi başı gelir artarken önce çevresel kirlilik artmakta, belirli bir refah seviyesine ulaşınca çevresel kirlilik azalmaktadır. Daha sonrasında kişi başı gelirin artışını sürdürmesiyle kişi başı çevresel kirlilik tekrar artmaktadır. Bu durum, belirli bir refah seviyesinden sonra çevresel kirliliğin azalacağını belirten Çevresel Kuznets Eğrisi hipoteziyle çelişmektedir. Çevresel Kuznets Eğrisi hipotezi geçersizdir.

Eşbütünleşme denkleminden elde edilen artık serisiyle oluşturulan Hata Düzeltme Modeli aşağıda yer almaktadır.

Tablo 8: Hata düzeltme modeli

\begin{tabular}{|c|c|c|c|c|c|c|c|c|c|}
\hline Test & \multicolumn{5}{|c|}{ Katsay1 } & \multicolumn{4}{|c|}{ Birleşik F testi } \\
\hline Değişken & $\Delta \ln Y$ & $\Delta \ln Y^{2}$ & $\Delta \ln Y^{3}$ & $\Delta \ln E$ & ECT & $\Delta \ln Y_{\mu-1}$ & $\Delta \ln Y_{\mu-}^{2}$ & $\Delta \ln Y_{\mu-}^{3}$ & $\Delta \ln E_{\mu-1}$ \\
\hline $\begin{array}{c}\text { Test } \\
\text { istatistiği }\end{array}$ & $\begin{array}{c}106.4534 \\
*\end{array}$ & $\begin{array}{c}11.6429 \\
*\end{array}$ & $\begin{array}{c}0.4238^{*} \\
*\end{array}$ & $\begin{array}{c}1.2118 \\
*\end{array}$ & $\begin{array}{c}0.8184 \\
*\end{array}$ & $\begin{array}{c}20.5776 \\
*\end{array}$ & $\begin{array}{c}20.4105 \\
*\end{array}$ & $\begin{array}{c}20.2517 \\
*\end{array}$ & $\begin{array}{c}67.6786 \\
*\end{array}$ \\
\hline
\end{tabular}

*, ${ }^{* *}$ sirasıyla \%1 ve \%5 düzeyinde anlamlılı̆̆ temsil etmektedir.

Kurulan hata düzeltme modelinde, eşbütünleşme denkleminden elde edilen artık serisinin(ECT) katsayısı $(0,-1)$ aralığında ve istatistiksel olarak anlamlıdır. Bu nedenle GSYİH, GSYİH2, GSYİH3 ve enerji tüketimi, CO2 emisyonunun Granger nedenidir. CO2 serisine etki eden bir şokun etkisi, bir dönemde \%81.84 oranında giderilmekte ve seri uzun dönem dengesine ulaşmaktadır. Birleşik $\mathrm{F}$ testi sonuçlarına göre serinin uzun dönem dengesine ulaşmasında tüm değişkenlerin etkisi vardır. GSYİH, GSYİH2, GSYİH3 ve enerji tüketimi, CO2'in güçlü Granger nedenidir.

\section{SONUÇ}

Çevresel Kuznets Eğrisi Hipotezi, gelişmekte olan bir ülkede yaşanan ekonomik büyüme ile ilk etapta çevresel kirliliğin artacağını, sonrasında belirli bir refah seviyesine ulaşılmasıyla, çevresel kirliliğin azalacağını öne sürmektedir. Literatürde farklı çevresel kirlilik değişkenleri ve farklı ekonometrik yöntemler kullanarak bu hipotezin geçerliliğini test eden birçok çalışma mevcuttur. Bu çalışmanın amacı, görece daha geniş bir örneklem dönemini kullanarak Çevresel Kuznets Eğrisi hipotezinin geçerliliğini yapısal kırılmalı eşbütünleşme tekniği ile test etmektir. Bu amaçla, ele alınan serilerde yapısal kırılmaya izin veren ZivotAndrews birim kök testi ile birim kök analizi yapılmış, serilerin birinci dereceden entegre (I(1)) olduğu tespit edilmiştir. Hansen İstikrarsızlık testi ile uzun dönem eşbütünleşme ilişkisinin istikrarlı olmadığı sonucuna ulaşılmıştır. $\mathrm{Bu}$ nedenle, yapısal kırılmalı eşbütünleşme tekniği olan Gregory-Hansen eşbütünleşme testi uygulanmıştır. Eşbütünleşme denkleminden elde edilen artık serisi ile Hata Düzeltme Modeli kurulmuş, nedensellik ilişkisi araştırılmıştır. 
Çalışmadan elde edilen bulgulara göre Türkiye için Çevresel Kuznets Eğrisi hipotezi geçerli değildir. Çevresel kirlilik ve ekonomik büyüme arasındaki ilişki, $\mathrm{N}$ biçimlidir. Hipotezde belirtildiği üzere ekonomik büyümenin yaşandığ1 ilk periyotta çevresel kirlilik artmakta ve belirli bir refah seviyesine ulaşınca azalmakta olsa da ilerleyen süreçte çevresel kirlilik tekrar artmaktadır. Bu çalışmanın benzerlerinden farkı, yapısal kırılmalı eşbütünleşme tekniği kullanarak görece daha uzun örneklem dönemini ele almasıdır. Sonuç olarak; Türkiye'de EKC hipotezinin geçersiz olması, çevresel kirliliği azaltıcı ekonomik büyüme performansının kendiliğinden oluşamayacağını, bu nedenle üretim sürecinin vazgeçilemez girdisi olan enerji tüketiminin Türkiye'nin de önemli bir potansiyele sahip olduğu yenilenebilir enerji kaynaklarıyla karşılanması gerektiği önem arz etmektedir. Elde edilen bulgular, Türkiye için iktisat politikaları oluşturulurken dikkate alınmalıdır.

\section{KAYNAKÇA}

Akbostanci, E., Türüt-Aşik, S., ve Tunç, G. I. (2009). The relationship between income and environment in Turkey: Is there an environmental Kuznets curve? Energy Policy, 37(3), 861-867.

Alam, M. M., Murad, M. W., Noman, A. H. M. ve Ozturk, I. (2016). Relationships among carbon emissions, economic growth, energy consumption and population growth: Testing Environmental Kuznets Curve hypothesis for Brazil, China, India and Indonesia. Ecological Indicators, 70, 466-479.

Al-Mulali, U., Weng-Wai, C., Sheau-Ting, L. ve Mohammed, A. H. (2015). Investigating the environmental Kuznets curve (EKC) hypothesis by utilizing the ecological footprint as an indicator of environmental degradation. Ecological Indicators, 48, 315-323.

Apergis, N. ve Ozturk, I. (2015). Testing environmental Kuznets curve hypothesis in Asian countries. Ecological Indicators, 52, 16-22.

Baek, J. (2015). Environmental Kuznets curve for CO2 emissions: The case of Arctic countries. Energy Economics, 50, 13-17.

Bölük, G. ve Mert, M. (2015). The renewable energy, growth and environmental Kuznets curve in Turkey: An ARDL approach. Renewable and Sustainable Energy Reviews, $52,587-595$.

Copeland, B. R. ve Taylor, M. S. (2004). Trade, Growth, and the Environment. Journal of Economic Literature, 42(1), 7-71.

Dinda, S. (2004). Environmental Kuznets Curve hypothesis: A survey. Ecological Economics, $49(4), 431-455$.

Esteve, V. ve Tamarit, C. (2012). Threshold cointegration and nonlinear adjustment between CO2and income: The Environmental Kuznets Curve in Spain, 1857-2007. Energy Economics, 34(6), 2148-2156.

Farhani, S., Mrizak, S., Chaibi, A. ve Rault, C. (2014). The environmental Kuznets curve and sustainability: A panel data analysis. Energy Policy, 71, 189-198. 
Fodha, M. ve Zaghdoud, O. (2010). Economic growth and pollutant emissions in Tunisia: An empirical analysis of the environmental Kuznets curve. Energy Policy, 38(2), 11501156.

Fosten, J., Morley, B. ve Taylor, T. (2012). Dynamic misspecification in the environmental Kuznets curve: Evidence from CO2and SO2emissions in the United Kingdom. Ecological Economics, 76, 25-33.

Gregory, A. W. ve Hansen, B. E. (1996). Residual-based tests for cointegration with regime shifts in models. Journal of Econometrics, 70, 99-126.

Grossman, G. M. ve Krueger, A. B (1991). Environmental impacts of a North American free trade agreement NBER WORKING PAPERS SERIES (3914).

Grossman G.M. ve Krueger A.B. (1995). Economic Growth and the Environment The Quarterly Journal of Economics 110(2), 353-377.

Hansen B.E. (1992). Test for Parameter Instability in Regressions with I(1) processes. Journal of Business \& Economic Statistics, 10(3), 321-335.

Hansen B.E. ve Gregory A.W. (1996). Tests for Cointegration in Models with Regime and Trend Shifts. Oxford Bulletin of Economics and Statistics, 58(3), 555-560

Iwata, H., Okada, K. ve Samreth, S. (2010). Empirical study on the environmental Kuznets curve for CO2 in France: The role of nuclear energy. Energy Policy, 38(8), 4057-4063.

Jalil, A. ve Mahmud, S. F. (2009). Environment Kuznets curve for CO2 emissions: A cointegration analysis for China. Energy Policy, 37(12), 5167-5172.

Kaika, D. ve Zervas, E. (2013). The Environmental Kuznets Curve (EKC) theory-Part A: Concept, causes and the CO2emissions case. Energy Policy, 62, 1392-1402.

Kijima, M., Nishide, K. ve Ohyama, A. (2010). Economic models for the environmental Kuznets curve: A survey. Journal of Economic Dynamics and Control, 34(7), 11871201.

Kuznets, S. (1955). Economic Growth and Income Inequality. The American Economic Review, 45(1), 1-28

Lau, L. S., Choong, C. K. ve Eng, Y. K. (2014). Investigation of the environmental Kuznets curve for carbon emissions in Malaysia: DO foreign direct investment and trade matter? Energy Policy, 68, 490-497.

Luzzati, T. ve Orsini, M. (2009). Investigating the energy-environmental Kuznets curve. Energy, 34(3), 291-300.

Nasir, M. ve Ur Rehman, F. (2011). Environmental Kuznets Curve for carbon emissions in Pakistan: An empirical investigation. Energy Policy, 39(3), 1857-1864.

Nelson, C. R. ve Plosser, C. I. (1982). Trends And Random Walks In Macroeconmic Time Series. Some evidence and imlications. Journal of Monetary Economics 10, 10(I 982), 139-162. 
Ozturk, I. ve Al-Mulali, U. (2015). Investigating the validity of the environmental Kuznets curve hypothesis in Cambodia. Ecological Indicators, 57, 324-330.

Saboori, B., Sulaiman, J. ve Mohd, S. (2012). Economic growth and CO2emissions in Malaysia: A cointegration analysis of the Environmental Kuznets Curve. Energy Policy, 51, 184-191.

Selden, T. M. ve Song, D. (1994). Environmental quality and development: Is there a kuznets curve for air pollution emissions? Journal of Environmental Economics and Management, 27, 147-162.

Stern, D. I. (2017). The environmental Kuznets curve after 25 years. Journal of Bioeconomics, 19(1), 7-28

Tiwari, A. K., Shahbaz, M. ve Adnan Hye, Q. M. (2013). The environmental Kuznets curve and the role of coal consumption in India: Cointegration and causality analysis in an open economy. Renewable and Sustainable Energy Reviews, 18, 519-527.

Zivot E. ve Andrews D.W.K. (1992) Further Evidence on the Great Crash, the Oil-Price Shock, and the Unit-Root Hypothesis. Journal of Business \& Economic Statistics, 20(1), 25-44. 